\section{False-positive mediastinal lymph node cytology due to translesional endoscopic ultrasound-guided fine-needle aspiration in a patient with Barrett's early cancer}

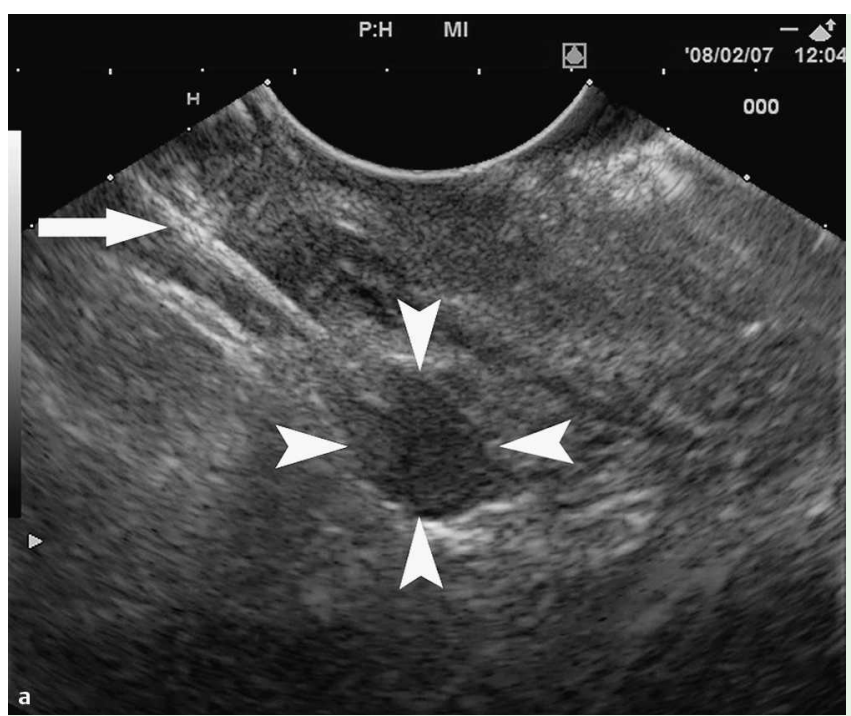

Fig. 1a Endoscopic ultrasound-guided fineneedle aspiration (EUSFNA) of an enlarged periesophageal lymph node (arrowheads, lymph node; arrow, needle).

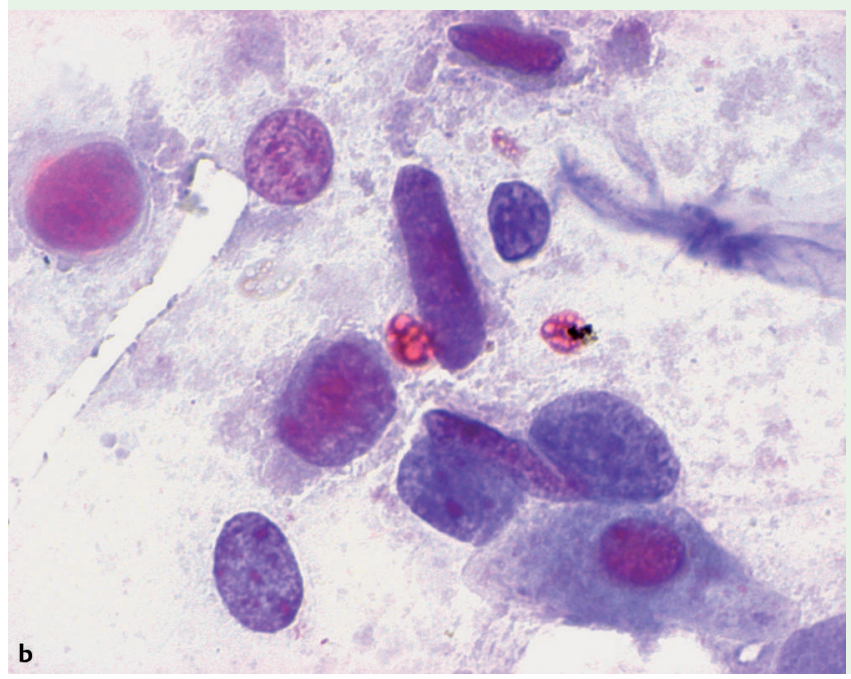

Endoscopic ultrasound-guided fine-needle aspiration (EUS-FNA) is an established technique for diagnosis and staging of gastrointestinal malignancies. In a recent meta-analysis, the specificity and sensitivity of the procedure in assessing mediastinal lymph nodes have been calculated to be $96 \%$ and $88 \%$, respectively [1].

We report upon a 47-year-old man with well-differentiated mucosal adenocarcinoma developed within a Barrett's esophagus. During clinical work-up a hypoechoic periesophageal lymph node, measuring $13 \mathrm{~mm}$ in diameter, was detected by endoscopic ultrasound, and EUS-FNA was performed ( $\bullet$ Fig. 1 a). Cytology revealed neoplastic epithelial cells ( $\bullet$ Fig. 1b) with marked aneuploidy according to DNA cytometry ( $\bullet$ Fig. 1 c), thus prompting esophagectomy with mediastinal lymph node dissection. The resection specimen confirmed the diagnosis of Barrett's adenocarcinoma confined to the mucosa. All the resected lymph nodes, however, were free of cancer despite extensive work-up including stepwise sectioning and immunohistochemical investigation. The Barrett's adenocarcinoma showed marked DNA aneuploidy with the same stemline ploidy values as those found in the FNA smears (॰ Fig. 1d).

Contaminating normal cells are a common finding in EUS-FNA specimens, depending on the site from which the targeted lesion is approached [2]. Welldocumented reports on cases with falsepositive EUS-FNA due to transtumoral puncture are, however, exceedingly rare. In a case similar to ours, Peng et al. [3] recently reported upon an esophageal squamous cell carcinoma patient with a cytologically suspicious lymph node on EUSFNA in whom all the lymph nodes were negative in subsequent surgical node staging and resection. On slide review, some moderately atypical squamous cells were identified which most likely represented luminal contaminants from dysplastic squamous epithelium.

To our knowledge, our case is the first to show false-positive EUS-FNA cytology of a mediastinal lymph node in a patient with Barrett's esophagus, putatively owing to mucosal adenocarcinoma at the puncture site. Awareness of this diagnostic pitfall in the endoscopic community may help to avoid misinterpretation with possible severe clinical consequences.

Endoscopy_UCTN_Code_CPL_1AL_2AF 


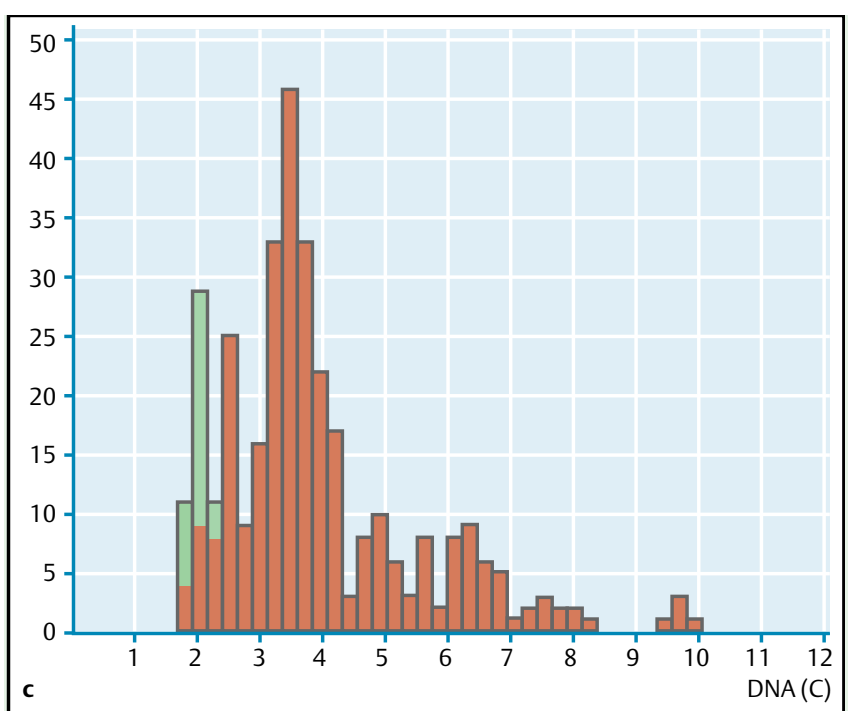

c DNA histogram of tumor cells obtained by EUS-FNA with multiple abnormal stemlines at $2.5 \mathrm{c}, 3.5 \mathrm{c}$ and $5.0 \mathrm{c}$ (red); lymphocytes as internal reference (green).

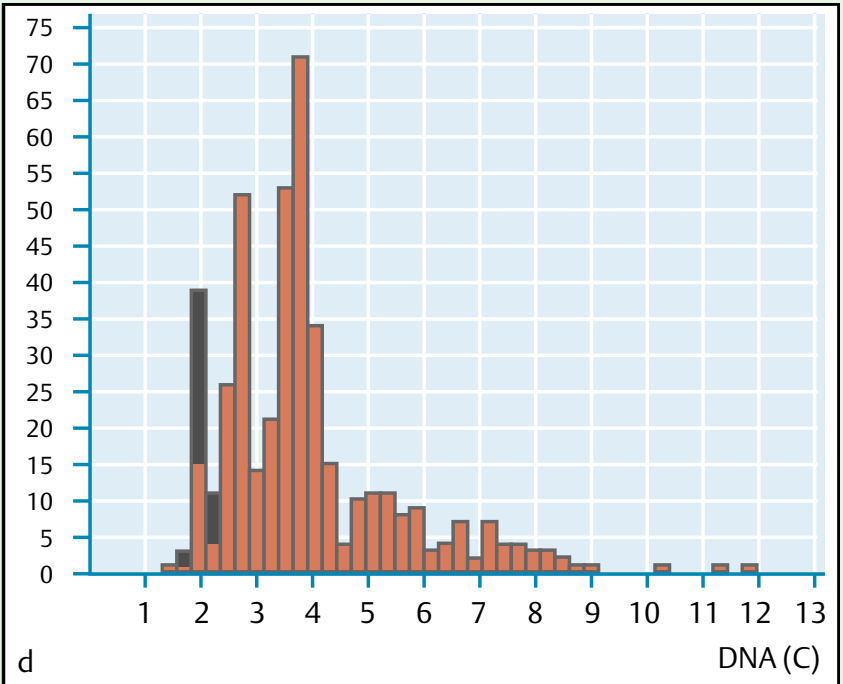

d DNA histogram of cells from Barrett's mucosal adenocarcinoma after enzymatic cell separation: nearly identical stemlines as in c; lymphocytes as internal reference (grey).

\section{Harbaum ${ }^{1}$, N. Pomjanski ${ }^{2}$,}

T. A. Hinterleitner ${ }^{3}$, A. Böcking ${ }^{2}$,

C. Langner ${ }^{1}$

1 Institute of Pathology, Medical University, Graz, Austria

2 Institute of Cytopathology, Heinrich Heine University Düsseldorf, Düsseldorf, Germany

3 Department of Internal Medicine, Division of Gastroenterology and Hepatology, Medical University, Graz, Austria
Bibliography

DOI 10.1055/s-0028-1119722

Endoscopy 2009; 41: E150-E151

(c) Georg Thieme Verlag KG Stuttgart · New York . ISSN 0013-726X

Corresponding author

\section{Langner, MD}

Institute of Pathology

Medical University Graz

Auenbruggerplatz 25

A-8036 Graz, Austria

Fax: +43-316-3853432

cord.langner@medunigraz.at 